\title{
Drill-Pipe Severing Tool with High-Temperature Explosive
}

\author{
Steven P. Koczan \\ William W. Patterson \\ Richard H. Rochester
}

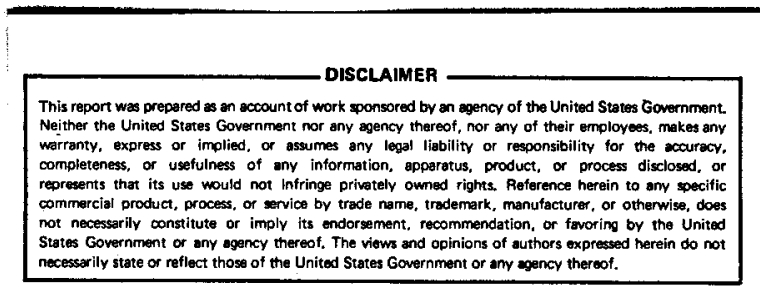

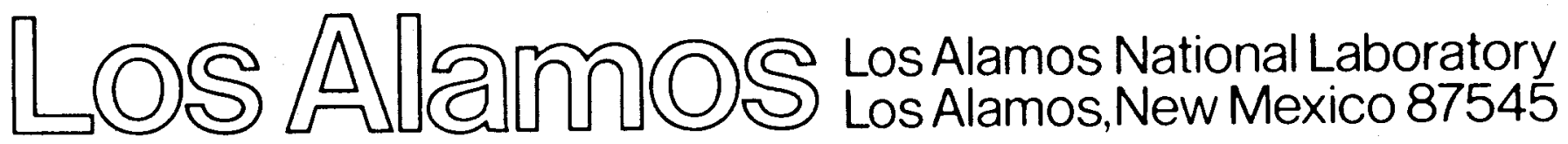




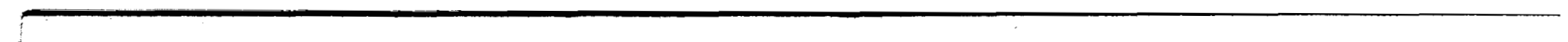




\section{DISCLAIMER}

This report was prepared as an account of work sponsored by an agency of the United States Government. Neither the United States Government nor any agency Thereof, nor any of their employees, makes any warranty, express or implied, or assumes any legal liability or responsibility for the accuracy, completeness, or usefulness of any information, apparatus, product, or process disclosed, or represents that its use would not infringe privately owned rights. Reference herein to any specific commercial product, process, or service by trade name, trademark, manufacturer, or otherwise does not necessarily constitute or imply its endorsement, recommendation, or favoring by the United States Government or any agency thereof. The views and opinions of authors expressed herein do not necessarily state or reflect those of the United States Government or any agency thereof. 


\section{DISCLAIMER}

Portions of this document may be illegible in electronic image products. Images are produced from the best available original document. 
CONTENTS

Page

ABSTRACT

I. INTRODUCTION

II. GENERAL DESCRIPTION OF TOOL

III. HIGH-TEMPERATURE DETONATOR

2

IV. DETONATOR SPECIFICATIONS

A. Performance

B. General

C. High-Temperature Explosive (PYX)

v. THE FIRING SYSTEM

A. The Uphole Control Unit

B. The Downhole Firing Module

VI. SYSTEM OPERATION

VII. USES

REFERENCES 

DRILL-PIPE SEVERING TOOL WITH HIGH-TEMPERATURE EXPLOSIVE

by

Steven P. Koczan, William W. Patterson, and Richard H. Rochester

\section{ABSTRACT}

This report describes a special-purpose borehole explosive tool designed to meet a need of the Los Alamos National Laboratory Hot Dry Rock (HDR) Geothermal Energy Development Program. This tool's particular purpose is to sever stuck drill pipe in deep $(>4500 \mathrm{~m})$, hot $\left(>320^{\circ} \mathrm{C}\right)$, water-filled wellbores. No commercial severing tools are known to us that can be operated at temperatures above $260^{\circ} \mathrm{C}$.

\section{INTRODUCTION}

The goal of the Laboratory's HDR program is to investigate and develop methods of extracting thermal energy from naturally hot granitic formations by circulating water through hydraulic fractures made in the HDR. Conventional oil field drilling techniques are used to make deep wellbores into the naturally occurring hot formations. This type of drilling places very large loads on drill strings, leading to occasional "twist-offs." To salvage the lower portion of the twisted-off and stuck drill string, an overshot tool generally is run into the hole to grapple the stuck portion. Then the sections of drill pipe below this overshot tool are explosively severed, and removed from the wellbore. At temperatures above $260^{\circ} \mathrm{C}$, commercial explosive severing systems either fail or detonate prematurely. The Los Alamos severing tool has been designed to operate in the HDR wellbores at higher temperatures $\left(\backsim 320^{\circ} \mathrm{C}\right)$. The high-temperature resistance was achieved by using a specially formulated high explosive (HE) as the high-temperature detonator, and a dewar-protected firing system, both of which are encased in a standard seamless steel tube 63.5-mm 0.d. 
x 50.8-mm i.d. (2.5-in. o.d. x 2.0-in. i.d.). The tool is operated through a seven-conductor, 7600-m-long, armored wireline that allows control of the downhole firing unit from the surface. The tool was designed to sever a 76-mm (3-in.) i.d. x 127-mm (5-in.) o.d. steel drill pipe. Changes in the shape of the HE lens may be adapted for other pipe sizes.

II. GENERAL DESCRIPTION OF TOOL

The sonde houses the shaped HE charge and the dewar that provides thermal protection for the firing system. The tool consists of a sinker bar nosepiece, a tubular section containing the explosive charge, the firing circuit, and at the tail end, a cablehead sub for attachment to the logging cablehead. Seals, capable of withstanding the wellbore fluid pressure $41379 \mathrm{kPa}$ ( $6000 \mathrm{psi}$ ) and a hole temperature of $320^{\circ} \mathrm{C}$, are located at the make-up connections of the tool.

Compressive springs (wave type and helical) are used to restrain both the dewar and the explosive charge detonator; each might tend to shift while being lowered into the hole, as well as swelling from thermal expansion as the tool heats up while in the wellbore (Figs. 1 and 2).

III. HIGH-TEMPERATURE DETONATOR ${ }^{1}$

The detonator (a Reynolds Industries modified RP-84) is a separate unit that contains only hexanitrostilbene (HNS) explosive. This relatively insensitive secondary explosive provides maximum safety from accidental detonation, as well as the stability required in a high-temperature environment. The detonator is a slapper initiator that contains $\approx 1 \mathrm{~g}$ of explosive. The high-current, high-power electrical energy pulse sent from the downhole firing module vaporizes a foil that accelerates a flyer, which in turn detonates the explosive instantaneously by impact energy. The explosive is pressed to near-crystal density and is completely separated from all conductive parts. This enhances the detonator's safety characteristics and improves its long-term stability.

The detonator is placed in a welded stainless steel housing, open at one end, with a Kemlon high-pressure feedthrough (16B-839) used to connect the high-voltage (HV) coaxial cable. Figure 3 gives the dimensions of a typical HNS detonator. 


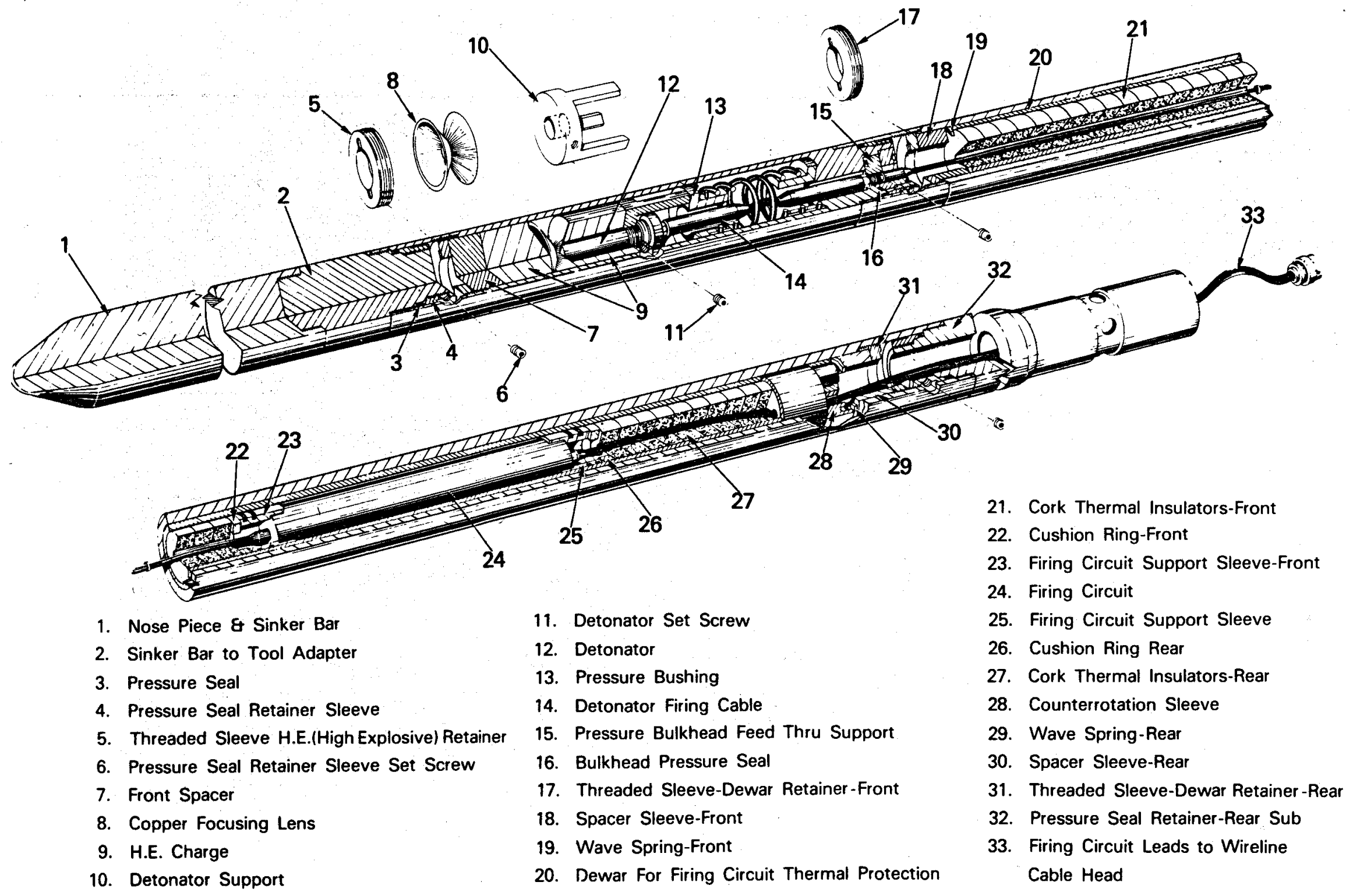

Fig. 1.

Explosive cut-off tool, 2.5 in. $0 . d . \times 95$ in. long, pressure limit 10000 psi, temperature 1 imit $600^{\circ} \mathrm{F}$. 


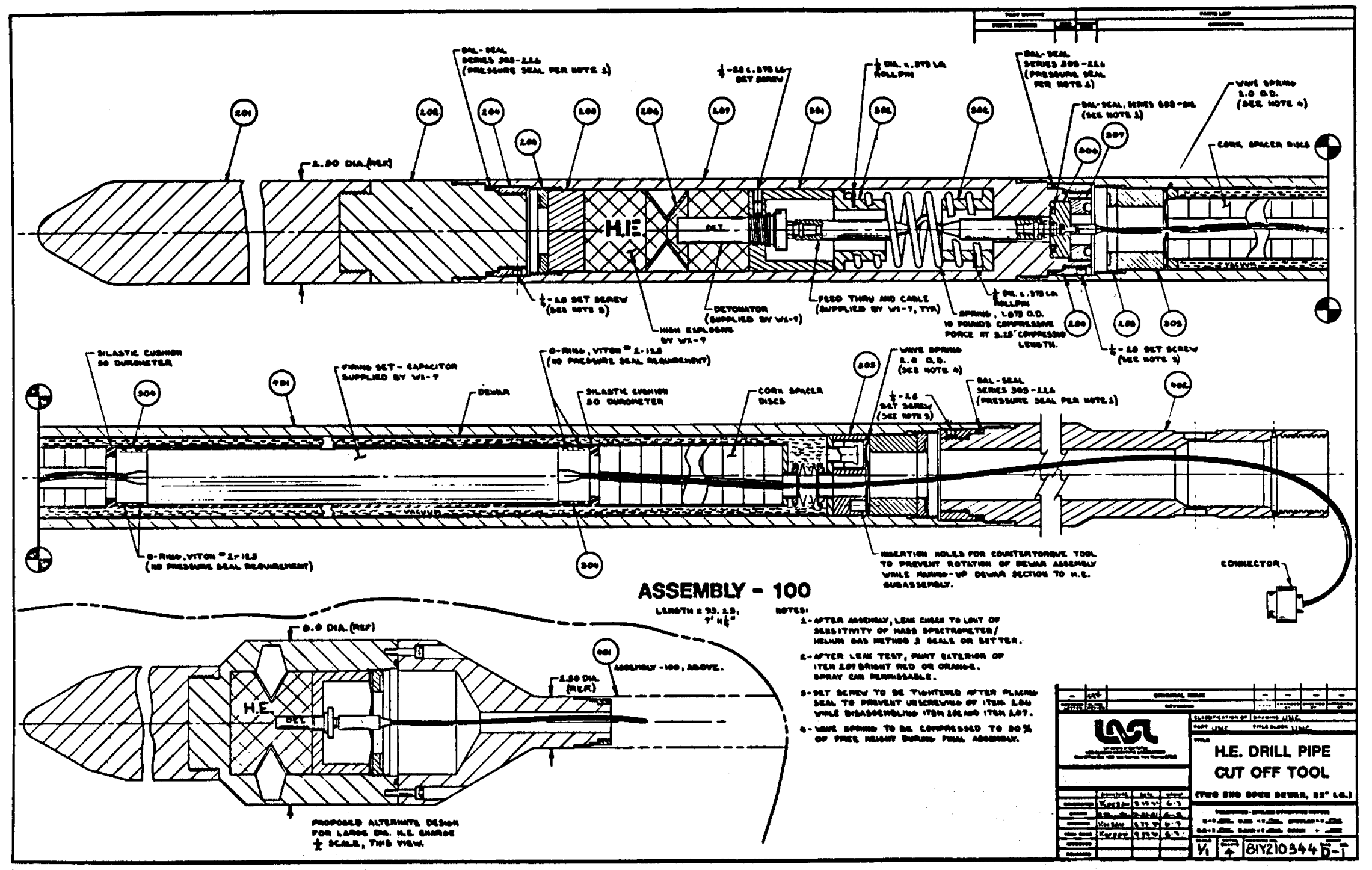

Fig. 2 .

Assembly of high-explosive drill pipe cut-off tool. 


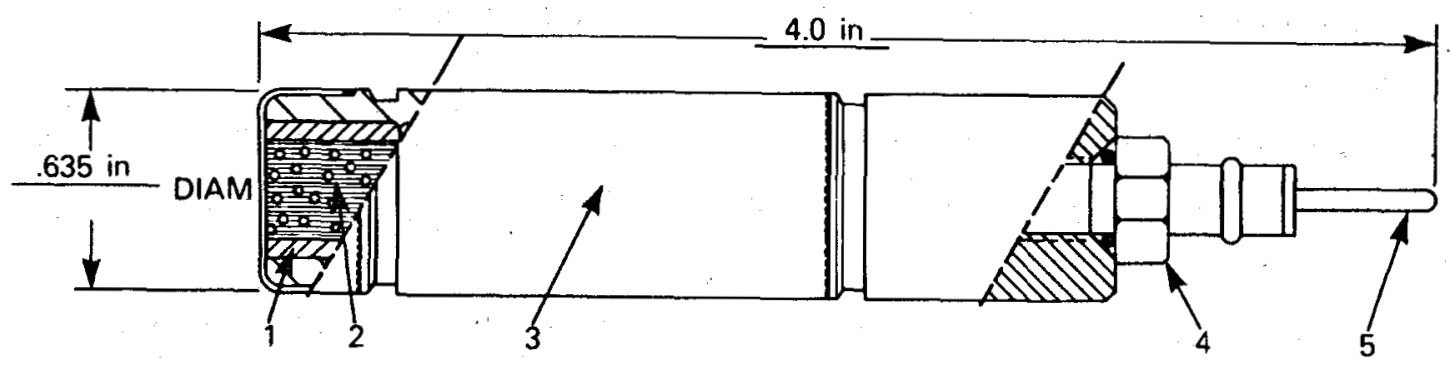

SECTION VIEW

1. PELLET ADAPTER

2. PELLET HNS

3. DETONATOR HOUSING STAINLESS STEEL
4. FEED THRU HOUSING

5. CONNECTS TO KEMLON PRODUCTS DEVELOPMENT CO. P:N 16-B-755

Fig. 3 .

Dimensions of a typical RP-84 HP HNS detonator.

\section{DETONATOR SPECIFICATIONS}

\section{A. Performance}

Threshold burst $\left(I_{b t h}\right)=<2200 \mathrm{~A}$

$I_{b t h}$ standard deviation $=<120 \mathrm{~A}$

All-fire burst current $=>3000 \mathrm{~A}$

These current levels are relatively high compared with Reynolds' EBW detonators; however, if the firing system (capacitor, trigger switch, cable, and connectors) is designed for minimum inductance and resistance, and is properly matched to the slapper initiation, the total required energy is not significantly greater than a standard EBW system. For example, a reliable slapper initiation system can be designed and built with a $1-\mu \mathrm{F}$ capacitor, charged to $4500 \mathrm{~V}$.

B. General

This initiator did not prematurely function or degrade when subjected to the following tests:

1. temperature survival of $2 \mathrm{~h}$ at $260^{\circ} \mathrm{C}$;

2. dielectric withstanding $500 \mathrm{~V}, 1-\mathrm{mA}$ leakage per MIL-1-23659 C;

3. static discharge test, $25000 \mathrm{~V}$ with 500-pfd capacitor and a $500-\Omega$ resistor per MIL-1-23659 C;

4. continuous static pressure, $34474 \mathrm{kPa}$ (5000 psi) for $\mathrm{P} / \mathrm{N}$ 167-8999;

5. $28-V$ dc applied to the foil for at least $1 \mathrm{~s}$ as specified in MIL-1-23659 C; 
6. maximum no-fire test, $500-\mathrm{V}$ dc for $50 \mathrm{~ms}$ across the foil per MIL-1-23659 C;

7. explosive function time from foil burst to shock output is $4.0 \mu \mathrm{s}$;

8. output characteristics that are similar to $R P-1 E B W$ detonator $(P / N$ 167-4314).

This initiator will not prematurely detonate, but it may degrade, deflagrate, or "dud" as a result of the following tests:

1. ac current test of $115-\mathrm{V}$ ac, 60 cycles connected directly across the foil for $30 \mathrm{~s}$;

2. continuous temperature $260^{\circ} \mathrm{C}$. C. High-Temperature Explosive (PYX)

During FY1979, M. D. Coburn of Los Alamos was on assignment as a visiting scientist to Eglin Air Force Base, Florida, where he initiated the development of some new thermally stable explosives. . One of the materials studied, 95/5-PYX/Kel-F 800 (AFX-521), ${ }^{2}$ was selected by the Air Force for interim qualification as a booster explosive. In addition to preparing the material required by the Air Force, we prepared enough of the explosive at Los Alamos for further evaluation in potential Department of Energy applications. The data obtained for this PBX, both at Los Alamos and at Eglin Air Force Base, are compared to those of two common booster explosives, Tetryl and PBX-9407, in Table I.

Evaluation of the results shown in Table I reveals that AFX-521 is a very unusual explosive. In addition to its unsurpassed thermal stability, 3 it is relatively insensitive to impact, spark, and pure shock (gap tests). It is as sensitive as PBX-9404 in the minimum priming test and its wedge-failure thickness is very small. This combination of properties suggests that AFX-521 is an excellent choice for a thermally stable booster application such as the HDR downhole explosive systems.

For the HDR application, we made the main shaped charge from PYX at a density of $1.7 \mathrm{~g} / \mathrm{cm}^{3}$ in the configurations shown in Fig. 1. One of the PYX pieces was bored to a diameter of $0.635 \mathrm{in}$. to accept the detonator. The entire charge was over designed so that we would be sure to sever the pipe. The principles of shaped charges are well known. The charge is contained in the downhole tool (illustrated in Fig. 1). The portion of the tool just above the pressure bulkhead is recoverable and can be reused. This particular type of charge severs drill pipe with a clean break (Fig. 4). 
TABLE I

PHYSICAL AND EXPLOSIVE PROPERTIES OF

95/5-PYX/KEL-F 800 (AFX-521)

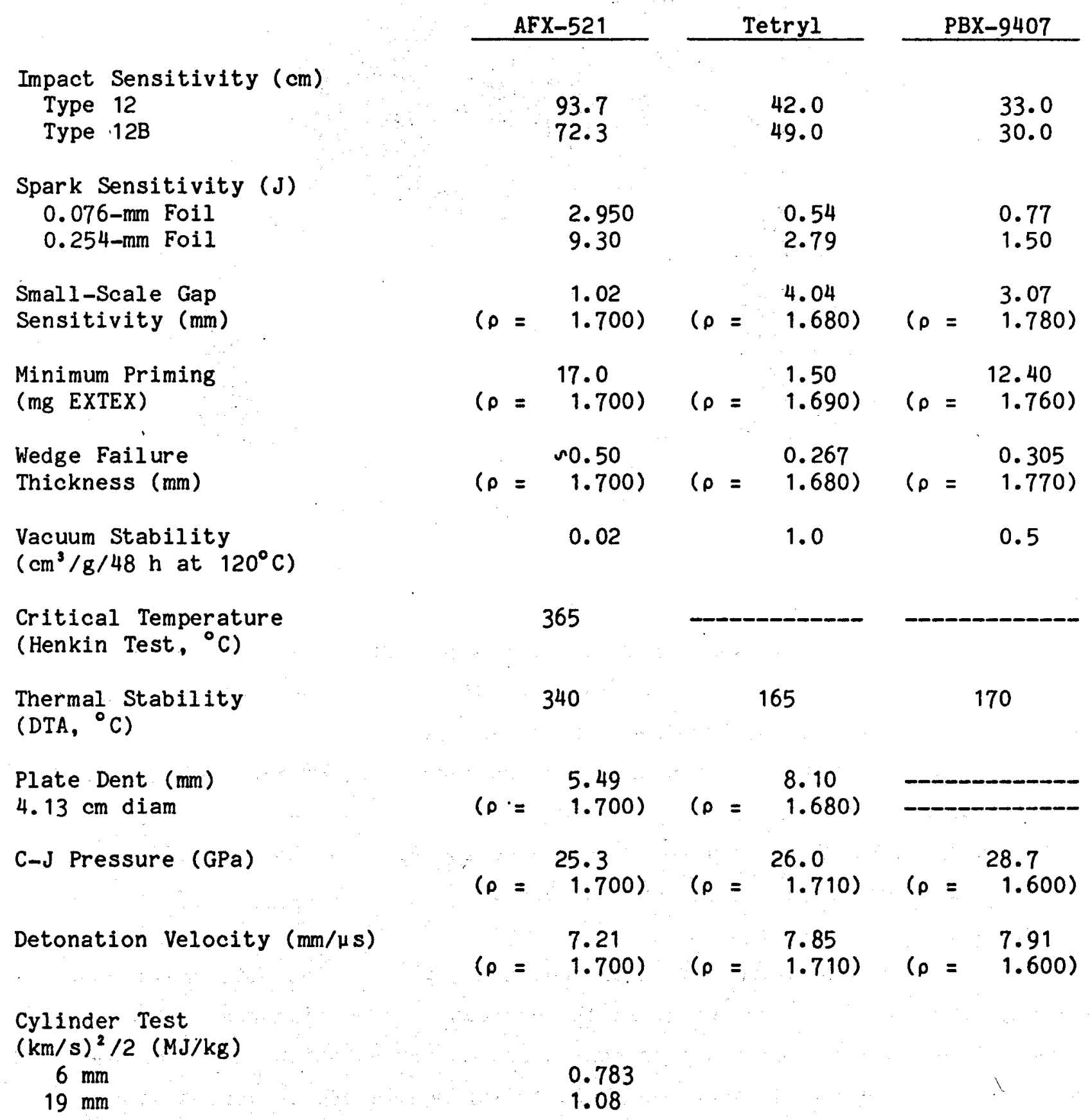




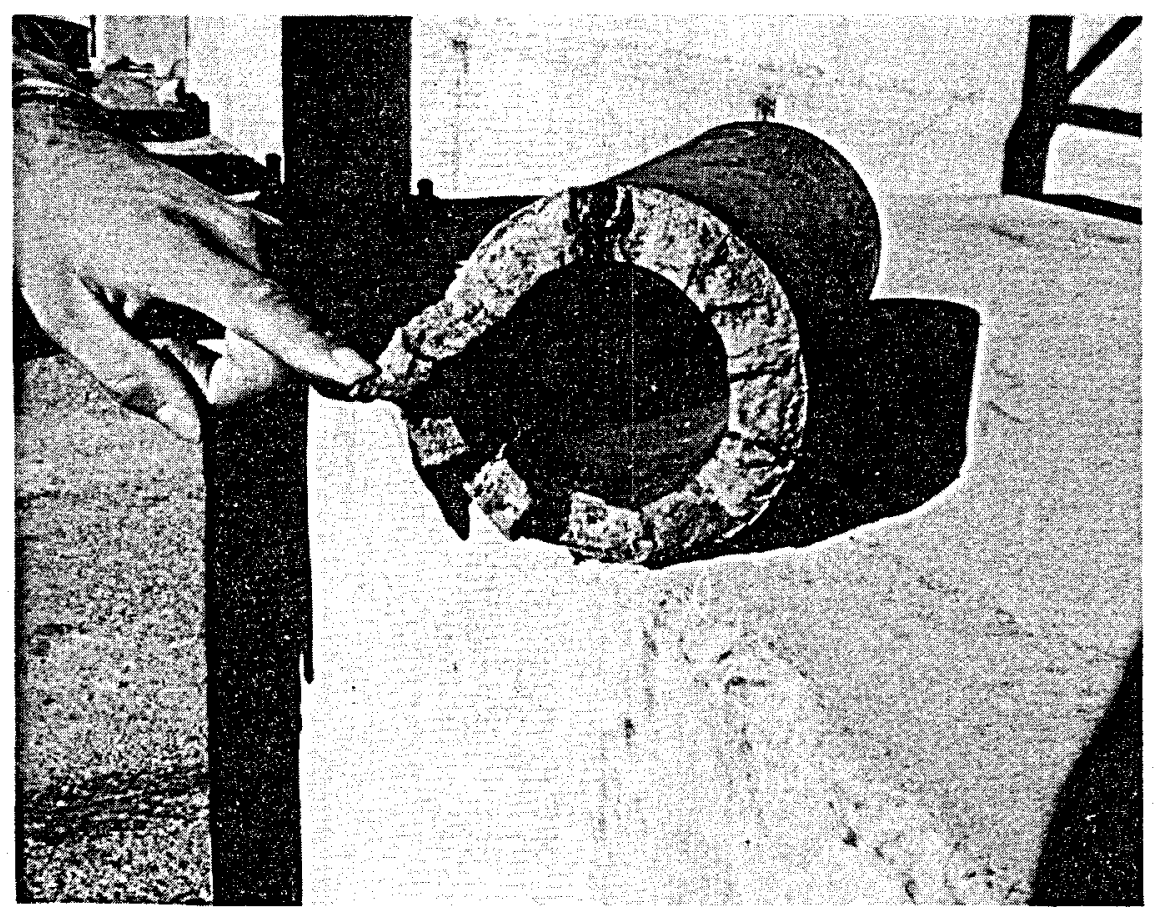

Fig. 4 .

Severed drill pipe using high-explosive charge.

V. THE FIRING SYSTEM

The firing unit is a Reynolds Industries Model FS20 capacitive discharge detonator firing system. The system consists of an uphole control unit and downhole firing module. Design features are as follows:

1. an uphole control unit with a current regulator, HV monitor, and safety interlock plug;

2. a downhole firing module (Firing Circuit, Fig. 1) that operates through a logging cable up to $7600 \mathrm{~m}$ (25 $000 \mathrm{ft}$ ) long.

A. The Uphole Control Unit

The $115-\mathrm{V}$ ac control unit is packaged in a $9 \times 5 \times 6$ in. moisture-sealed carrying case. On the front panel is the connector that joins the unit to the firing module, ac power outlet, and monitoring instrumentation. The unit meter monitors the HV developed in the downhole firing module and serves as an indicator that the unit has fired. Switches arm and fire the system. A safety interlock plug renders the control box inoperative when removed. 
Internally, the control box contains a 120-V ac, 300-mA current-regulated power supply and associated control circuitry:

B. The Downhole Firing Madule

The firing module (circuitry shown in Fig. 1) is housed in a 1-3/8-in.-diam $x$ 10-in.-long aluminum tube that is potted to protect it from vibration and shock while the tool is lowered into the borehole.

Electrically, the firing module consists of an inverter and a voltage tripler charging $a .5-\mu F$ energy storage capacitor to $\$ 4500-V$ dc. An overvoltage spark gap is provided at the output, which self triggers when the HV is approximately $4500-\mathrm{V}$ dc.

Power requirements downhole are $\backsim 20-V$ dc, $300 \mathrm{~mA}$ to power the inverter. Power is supplied from the uphole control unit. Input voltages uphole depend on cable length, temperature, and cable resistance to ground. The logging cable now in use has seven conductors, is $7600 \mathrm{~m}$ (25 $000 \mathrm{ft}$ ) 1ong, has a resistance of $\sim 250 \Omega$, and a minimum resistance of $1 M_{\Omega}$ to ground.

Operation of the downhole firing module requires three conductors. These conductors are used for a $\sim 20-\mathrm{V}$ ac input, HV monitor, and ground.

A dewar and pressure vessel (Figs. 1 and 2) are used to protect the firing module from the high-pressure/high-temperature downhole environment.

\section{SYSTEM OPERATION}

Operation of the system is as follows.

1. Connect power plug to $110-\mathrm{V}$ ac.

2. Mate shorting plug to "safety interlock" connector.

3. Depress and hold arm/fire push buttons simultaneously.

4. Continue to hold buttons until voltage on meter has stopped rising and makes an abrupt drop indicating the unit has fired.

VII. USES

This particular tool was designed for use in the high-temperature HDR holes. However, with minor adjustments in charge size, diameter, etc., the severing tool design could be applied to numerous situations where severing in harsh environments is necessary. 
In Fig. 2 a proposed alternate design illustrates size variations possible for use with the basic design concept.

\section{REFERENCES}

1. W. W. Patterson, D. R. Deam, H. J. MacDonald, and R. H. Rochester, "Capacitive Discharge Firing System for Providing Acoustic Source in the Hot Dry Rock Geothermal Energy Development Project," Los Alamos Scientific Laboratory report LA-7761-MS (July 1979).

2. M. D. Coburn, D. J. Hufnagle, and D. L. Loverro, "Development of AFX-511 and AFX-521, Two New Thermally Stable Explosives," Los Alamos Scientific Laboratory report LA-8115-MS (February 1980).

3. J. F. Baytos, "High-Temperature Vacuum Stability Tests of Explosives," Los Alamos Scientific Laboratory report LA-5829-MS (January 1975). 